\title{
Evolution of Programs to Improve Transfers between Hospitals and Nursing Homes at the Community Level
}

\author{
Ronald Lagoe ${ }^{*}$, Louise Pernisi², Dorothy Haag ${ }^{3}$, Barbara Drapola ${ }^{4}$ \\ ${ }^{1}$ Hospital Executive Council, Syracuse, NY, USA \\ ${ }^{2}$ Upstate University Hospital, Syracuse, NY, USA \\ ${ }^{3}$ St. Joseph's Hospital Health Center, Syracuse, NY, USA \\ ${ }^{4}$ Crouse Hospital, Syracuse, NY, USA \\ Email: ${ }^{*}$ Hospexcl@cnymail.com
}

Received 30 May 2015; accepted 4 July 2015; published 9 July 2015

Copyright (C) 2015 by authors and Scientific Research Publishing Inc.

This work is licensed under the Creative Commons Attribution International License (CC BY). http://creativecommons.org/licenses/by/4.0/

c) (i) Open Access

\begin{abstract}
This study described the evolution of programs to improve the efficiency of patient movement between hospitals and nursing homes in the metropolitan area of Syracuse, New York. These programs were needed in order to improve coordination among providers in the absence of networks that included both acute and long term care providers. The mechanisms included the exchange of data and monitoring the movement of Difficult to Place patients from hospitals to nursing homes. Between 2006 and 2014, the annual number of Difficult to Place patients increased from 983 to 1836. During this period, annual hospital medical/surgical discharges increased by 7.5 percent, severity of illness increased by 13.7 percent, and the population aged 65 years and over increased by 9.8 percent. Most of the Difficult to Place patients were admitted by the four largest facilities in the community, which accounted for 60 percent of the nursing home beds. The initiatives also included Subacute and Complex Care Programs that provided financial incentives for admission of certain types of patients, such as intravenous therapy and extensive wound care. The programs described how these programs were implemented using minimal financial resources and without adding positions to the participating provider organizations.
\end{abstract}

\section{Keywords}

Hospitals, Nursing Homes, Long Term Care, Hospital Lengths of Stay

\footnotetext{
${ }^{*}$ Corresponding author.
} 


\section{Introduction}

In the United States, the need for provider efficiency in the delivery of health care is increasing. Although the rate of increase in health care expenses has slowed in recent years, the pressure on providers for efficiency in the delivery of care continues to rise [1] [2].

This need may be most apparent for acute hospitals, historically one of the most expensive sectors of health care. The aging of populations, as well as rising costs of labor, pharmaceuticals, and technology, have continued to push hospitals to limit utilization and related expenses [3] [4]. These developments have stimulated increasing levels of coordination between hospitals and long term care providers because of the need to discharge acute care patients to appropriate levels of care [5] [6].

Historically, community care programs were developed in the United States to coordinate the care of patients among hospitals, home health agencies, and nursing homes. These programs did not have a major impact on hospital patients with long stays in nursing homes [7] [8].

Since that time, approaches to coordinating acute and long term care services have been developed using networks of providers or disease management. Some of these network models have produced positive results because they control provider organizations [5] [9].

Most recently, efforts to improve hospital efficiency and outcomes have also supported efforts to improve coordination between acute and long term care services. These efforts have included the development of Accountable Care Organizations to reduce the expenses of care for Medicare and other populations. They also have been supported by efforts to address financial penalties for excess hospital readmissions [10] [11].

This history of this subject suggests that the focus of efforts to improve the efficiency of care continues to exist at the community level. In this context, the interests of patients are best served by the coordination of care among individual providers.

\section{Population}

This study concerned the evolution of programs to improve the efficiency of moving patients between hospitals and nursing homes in the metropolitan area of Syracuse, New York. This area includes three acute hospitals, Crouse Hospital (19,919 discharges excluding well newborns in 2014), St. Joseph's Hospital Health Center (25,532 discharges), and Upstate University Hospital (26,649 discharges). These hospitals work with 12 nursing homes in the City of Syracuse and Onondaga County, as well as 25 nursing homes in the surrounding counties.

The Syracuse hospitals provide primary and secondary acute care to a population of approximately 600,000. They also serve as the tertiary referral center for the Central New York Health Service Area, with a population of approximately 1,400,000.

Historically, the Syracuse hospitals have worked cooperatively to improve the efficiency and outcomes of care in the service area [12]. A major focus of these efforts has been reduction of inpatient stays for discharges to nursing homes. This population has been the largest source of excess stays, compared with severity adjusted national averages [13].

In addition to the need for efficiency of patient utilization in the health care system, the impetus for community wide efforts among acute and long term care providers has been generated by the lack of hospital control of large numbers of nursing home beds in Syracuse. For much of the period of this study, the Syracuse hospitals owned only about 14 percent of the nursing home beds in the community, compared with much higher levels elsewhere in the nation.

\section{Programs Addressed by the Study}

During the 1990's, the Syracuse hospitals and most of the nursing homes located in Onondaga County developed the System Efficiency Program. This effort focused on Difficult to Place Patients, those individuals in the Syracuse hospitals who experienced difficulties in obtaining access to residential long term care after discharge [14]. The program was designed to increase numbers of these patients admitted by local home health agencies and nursing homes through distribution of data concerning this population. The data were intended to increase awareness of the needs of this population and stimulate efforts between hospitals and long term care providers to address them.

The System Efficiency Program involved the identification of Difficult to Place Patients by each of the hos- 
pital care management departments, based on the specific experiences of each hospital in obtaining placement in home health care services or nursing homes. Lists of these patients, with names encrypted, were sent by each care management department to the Hospital Executive Council once each week. The lists included demographic and utilization indicators for each patient such as age, principal long term care diagnosis, hospital admission date, and payor status. For those patients who had been discharged during the previous seven days, the lists also included the discharge status of the patient, such as a nursing home, home, or expired [15].

The Hospital Executive Council staff was responsible for distributing copies of the Difficult to Place lists once each week to every home health agency and nursing home in the Central New York region. This distribution was carried out by electronic mail. At the end of each month, the Council was also responsible for distributing a table summarizing numbers of Difficult to Place Admissions, as well as total new admissions by hospital of origin and nursing home that had occurred during the month [15].

Between 2002 and 2008, the distribution of the Difficult to Place lists and related activities was associated with a 14.1 percent increase, from 822 to 1164 , in the annual numbers of these patients admitted by nursing homes in the service area of the Syracuse hospitals. During the same period, the percentage of new admissions that were Difficult to Place in the service area of the hospitals increased from 17.6 to 18.7. The slow rate of increase resulted, in part, difficulties in program implementation and the development of consistent data [15].

In addition to the System Efficiency/Difficult to Place Programs, the Syracuse hospitals and area nursing homes developed a series of Subacute Programs to expedite the movement of patients requiring specific types of therapies in the health care system. These types of patients had been identified through ongoing planning activities and the collection of data by hospitals and nursing homes. They included the use of intravenous medications, other high cost medications, extensive wound care, bariatric care, and off site transportation [15].

Through a legal opinion secured by the Hospital Executive Council, the Subacute Programs were set up with the following components.

Need for participation of each patient in the program would be agreed to by the Care Management Director of the hospital and the Director of Admissions of the nursing home involved.

All funding would be developed and distributed through a community wide pool maintained by the Hospital Executive Council.

Funding for each program would be provided at a uniform rate per patient.

Funding would be provided for a minimum of three patients per facility annually.

Implementation of the Subacute Programs occurred between 2003 and 2006. The Oral Medications Program was phased out in 2012 because it was not contributing to reduction of extended hospital stays for patients discharged to nursing homes. Between 2014 and 2015, a series of Complex Care Programs were implemented for patients who required services also known as long term acute care such as multiple intravenous medications and wound vacs plus intravenous medications.

\section{Study Methodology}

This study focused on analysis of the impact of the Difficult to Place and Subacute/Complex Care Programs between 2006 and 2014. It involved data developed through continued implementation of the programs and related information using simple descriptive statistics.

The initial component of the analysis identified annual numbers of Difficult to Place patients identified in the Syracuse hospitals between 2006 and 2014. It also included annual numbers of medical and surgical patients, as well as elderly residents of the service area.

The second component of the analysis involved identification of numbers of Difficult to Place patients admitted by nursing homes in the service area of the Syracuse hospitals during 2006, 2010, and 2014. It involved analysis of changes in these data in comparison with total new admissions to nursing homes by long term care facility.

The third component of the analysis involved a review of utilization of the Subacute and Complex Care Programs between 2006 and 2014. It also included additional information concerning development of the Complex Care Programs in 2014 and 2015.

The fourth component of the analysis focused on numbers of adult medicine and adult surgery patients discharged to nursing homes and lengths of stay for this population between 2006 and 2014. This analysis included hospital mean stays, severity adjusted national average stays, length of stay differences between these indicators, and length of stay differences translated into patient days differences. For purposes of this analysis, the severity 
adjusted lengths of stay and comparisons with national averages were carried out using the 3M All Patients Refined Diagnosis Related Group system. These data provided information concerning changes in lengths of stay for this population, as well as changes in the severity of illness of this population, over time.

\section{Results}

The initial component of the study focused on changes in numbers of Difficult to Place patients admitted to nursing homes from the Syracuse hospitals with changes in other utilization and demographic indicators. Related information is summarized in Table 1.

These data demonstrated that the total number of Difficult to Place patients in the Syracuse hospitals increased by 86.6 percent, from 983 to 1836, between 2006 and 2014. This population generated the largest component of the increase in total new admissions to nursing homes, which rose by 14.4 percent. By comparison, the number of non Difficult to Place admissions to nursing homes in the Syracuse hospitals increased by only 1.3 percent, from 5346 to 5431 , during the same time period.

The data in Table 1 suggested some of the factors which contributed to the increase in Difficult to Place Patients between 2006 and 2015. The number of medical-surgical discharges in the Syracuse hospitals increased by 7.5 percent. The increase in the number of discharges amounted to 10.9 percent between 2006 and 2012 . The 2012 discharge volume was higher than the 2014 total because of the implementation of payer regulations concerning medical observation patients in 2013.

The data also identified increases in demographics in the service area of the Syracuse hospitals between 2006 and 2014. The population aged 65 years and over increased by 9.8 percent, largely because of the aging of those born after 1945, the post war baby boom population. The population aged 75 years and over, the Depression generation and before, declined in numbers during this time period.

Additional analysis of the data demonstrated that the severity of illness of medical-surgical patients discharged to nursing homes increased in the Syracuse hospitals between 2006 and 2014. This increase amounted to 24.2 percent for adult medicine patients and 3.1 percent for adult surgery patients, an average of 13.7 percent for the combined services.

These data suggested that the increase in numbers of Difficult to Place Patients admitted to nursing homes from the Syracuse hospitals between 2006 and 2014 was substantial. Less than half of this increase, 31.0 percent, could be attributed to a combination of additional medical-surgical discharges, 7.5 percent, additional elderly residents, 9.8 percent, and higher medical-surgical severity of illness for discharges to nursing homes, 13.7 percent.

Table 1. Difficult to place admissions to nursing homes, Syracuse, New York hospitals 2006-2014.

\begin{tabular}{|c|c|c|c|c|c|c|}
\hline & 2006 & 2008 & 2010 & 2012 & 2014 & $\begin{array}{c}\text { Percent } \\
\text { Difference } \\
\text { 2006-2014 }\end{array}$ \\
\hline \multicolumn{7}{|l|}{ Admissions to Nursing Homes } \\
\hline Difficult to Place Admissions & 983 & 1164 & 1338 & 1564 & 1836 & 86.6 \\
\hline Total New Admissions & 6329 & 6236 & 6473 & 6656 & 7267 & 14.4 \\
\hline Rate & 15.5 & 18.7 & 20.7 & 23.5 & 25.3 & 63.2 \\
\hline Hospital Medical/Surgical Discharges & 50,209 & 47,818 & 51,363 & 55,664 & 53,973 & 7.5 \\
\hline \multicolumn{7}{|c|}{ Severity of Illness/Discharges to Nursing Homes } \\
\hline Adult Medicine & 1.0410 & 1.1067 & 1.1998 & 1.2588 & 1.2933 & 24.2 \\
\hline Adult Surgery & 2.6634 & 2.7587 & 2.7741 & 2.7512 & 2.7472 & 3.1 \\
\hline \multicolumn{7}{|l|}{ Population } \\
\hline Ages 65 Years \& Over & 107,424 & 108,667 & 109,910 & 113,932 & 117,956 & 9.8 \\
\hline Ages 75 Years \& Over & 52,745 & 53,415 & 54,083 & 53,261 & 52,437 & -0.6 \\
\hline
\end{tabular}

Population data based on Onondaga, Cayuga, Cortland, Madison, and Oswego Counties. Sources: Hospital Executive Council data; New York State Statistical Information System data. 
The second and third components of the analysis focused on programs developed by the Syracuse hospitals to improve the efficiency of care by expediting the movement of patients to nursing homes. Information concerning Difficult to Place admissions by individual nursing homes between 2006 and 2014 is summarized in Table 2. These data include numbers of these patients admitted and the percent of total new admissions that these patients accounted for at each facility that were provided to hospitals and nursing homes in weekly and monthly reports.

This information demonstrated that, during 2014, the largest nursing homes in Onondaga County accounted for the highest numbers of Difficult to Place admissions. These facilities had different forms of sponsorship including James Square Health and Rehabilitation Center, a proprietary; Loretto and St. Camillus Health and Rehabilitation Center, private not for profits; and Van Duyn Home and Hospital, a County nursing home. These facilities accounted for approximately 60 percent of the nursing home beds in the service area of the hospitals. Of these nursing homes, James Square generated the highest number of Difficult to Place admissions and the highest rate of these admissions in 2014. It also produced the highest rate of increase in Difficult to Place admissions between 2006 and 2014. Numbers of Difficult to Place Admissions also increased at Loretto and St. Camillus. In 2014, the rate for Loretto was above the community average, while the rate for St. Camillus was slightly below it.

The data in Table 2 also indicated that Difficult to Place Admission levels were substantial for two hospital owned long term care facilities, the Iroquois Nursing Home and Rosewood Heights, which accounted for approximately 14 percent of the nursing home beds in the area. Numbers and rates of Difficult to Place Admissions to the Iroquois Nursing Home increased during the period. Difficult to Place Admissions for Rosewood Heights increased, and then declined because of the phase out of this facility.

The data in Table 2 demonstrated that the lowest Difficult to Place admission numbers and rates during the period were generated by two proprietary nursing homes, Birchwood Health Care Center and The Crossings, and two not for profit facilities, the Syracuse Home Association and Menorah Park. The percentages of new admissions that were Difficult to Place at these facilities were lower than 15 percent throughout the period of the

Table 2. Difficult to place nursing home placements, Syracuse hospitals 2006, 2010, 2014.

\begin{tabular}{|c|c|c|c|c|c|c|c|c|c|}
\hline \multirow[b]{2}{*}{ Nursing Home } & \multicolumn{3}{|c|}{2006} & \multicolumn{3}{|c|}{2010} & \multicolumn{3}{|c|}{2014} \\
\hline & $\begin{array}{l}\text { Difficult } \\
\text { to Place } \\
\text { Admissions }\end{array}$ & $\begin{array}{l}\text { Total New } \\
\text { Admissions }\end{array}$ & Rate & $\begin{array}{l}\text { Difficult } \\
\text { to Place } \\
\text { Admissions }\end{array}$ & $\begin{array}{l}\text { Total New } \\
\text { Admissions }\end{array}$ & Rate & $\begin{array}{l}\text { Difficult } \\
\text { to Place } \\
\text { Admissions }\end{array}$ & $\begin{array}{l}\text { Total New } \\
\text { Admissions }\end{array}$ & Rate \\
\hline Birchwood & 20 & 733 & 2.7 & 24 & 586 & 4.1 & 21 & 547 & 3.8 \\
\hline Central Park & 37 & 103 & 35.9 & 90 & 196 & 45.9 & 77 & 156 & 49.4 \\
\hline The Crossings & 18 & 184 & 9.8 & 30 & 245 & 12.2 & 29 & 213 & 13.6 \\
\hline Iroquois Nursing Home & 58 & 298 & 19.5 & 107 & 392 & 27.3 & 137 & 419 & 32.7 \\
\hline James Square Nursing Home & 74 & 496 & 14.9 & 103 & 445 & 23.1 & 322 & 860 & 37.4 \\
\hline Menorah Park & 9 & 187 & 4.8 & 6 & 160 & 3.8 & 17 & 147 & 11.6 \\
\hline Loretto & 246 & 1232 & 20.0 & 178 & 871 & 20.4 & 297 & 989 & 30.0 \\
\hline Rosewood Heights & 136 & 348 & 39.1 & 167 & 347 & 48.1 & 13 & 42 & 31.0 \\
\hline St. Camillus Health \& Rehab & 98 & 887 & 11.0 & 105 & 706 & 14.9 & 168 & 729 & 23.0 \\
\hline Sunnyside Nursing Home & 21 & 81 & 25.9 & 10 & 80 & 12.5 & 58 & 226 & 25.7 \\
\hline Syracuse Home Association & 25 & 310 & 8.1 & 24 & 398 & 6.0 & 34 & 425 & 8.0 \\
\hline Van Duyn Home \& Hospital & 61 & 350 & 17.4 & 112 & 310 & 36.1 & 109 & 433 & 25.2 \\
\hline Out of County & 180 & 1120 & 16.1 & 382 & 1727 & 22.1 & 554 & 2081 & 26.6 \\
\hline Total & 983 & 6329 & 15.5 & 1338 & 6463 & 20.7 & 1836 & 7267 & 25.3 \\
\hline
\end{tabular}

Rates are based on actual difficult to place admissions divided by total new admissions. Difficult to place admissions included returns. Source: Hospital Executive Council. 
Table 3. Long term care Subacute and complex care program utilization, Syracuse hospitals 2006, 2008, 2010, 2012, 2014.

\begin{tabular}{lccccc}
\hline & 2006 & 2008 & 2010 & 2012 & 2014 \\
\hline Intravenous Medications & 60 & 54 & 40 & 39 & 52 \\
Oral \& Subcutaneous Medications & 134 & 75 & 61 & 24 & - \\
Enhanced Medications & - & 22 & 14 & 9 & 35 \\
Extensive Wound Care & 18 & 9 & 7 & 7 & 25 \\
Bariatric Care & - & 10 & 17 & 17 & 7 \\
Off-Site Services & - & 15 & 27 & 13 & 25 \\
Complex Care & - & - & - & - & 3 \\
Total & 212 & 185 & 166 & 109 & 147 \\
\hline
\end{tabular}

Source: Hospital Executive Council.

data. For Birchwood and the Syracuse Home Association, these percentages were below 10 percent.

Information concerning use of the Subacute and Complex Care Programs between the Syracuse hospitals and area nursing homes between 2006 and 2014 is summarized in Table 3. These data recognize the implementation of a number of these programs after 2006 and the elimination of the Oral Medications Program in 2014.

These data demonstrate that most utilization of these programs involved the provision of medications and related services in nursing homes in order to expedite hospital discharges. These included the Intravenous Medications Program, which supported patients by providing single pharmaceuticals and the Enhanced Medications Programs, which involved specific medications and dosages of specific intravenous and oral medications. The original Oral Medications Programs was phased out because its impact on hospital lengths of stay could not be identified.

Additional Subacute Programs supported wound vac services, Bariatric Care, and transportation from nursing homes for dialysis and radiation oncology. Utilization of each of these services increased during the period, especially between 2012 and 2014.

The development of Complex Care Programs by the Syracuse hospitals and area nursing homes occurred at the end of this period and was not reflected fully in the data for this period. These programs included long term acute care services such as multiple antibiotics, wound care including both pharmaceuticals and wound vacs, mental health services, and other programs. The Hospital Executive Council and the three hospitals implemented a series of Complex Care Programs in February 2015. St. Joseph’s Hospital Health Center and Loretto had implemented a program involving only the two providers in 2014.

The fourth component of the analysis focused on the impact of the Difficult to Place and Subacute/Complex Care Programs on lengths of stay for discharges to nursing homes in the Syracuse hospitals. Data concerning adult medicine and adult surgery lengths of stay in the combined hospitals, compared with severity adjusted national averages, are summarized in Table 4.

This information demonstrated that adult medicine lengths of stay in the Syracuse hospitals increased by 17.9 percent, from 7.56 to 8.91 days, between 2006 and 2014. During the same period, the national average for stays with the same severity of illness increased by 17.0 percent, from 5.24 to 6.13 days. The data also indicated that lengths of stay for the two populations increased at almost the same rates between 2006 and 2012, as demonstrated by the consistent length of stay differences during this period. In effect, the increase in stays offset the impact of an increase in severity of illness that occurred during the eight year period.

The data in Table 4 demonstrated that adult surgery lengths of stay for discharges to nursing homes declined by 4.0 percent, from 10.61 to 10.19 days, between 2006 and 2014. During this period, the national average for stays with the same severity of illness increased by 4.2 percent, from 7.31 to 7.62 days. The combined impact of these changes caused the difference between the hospital and national average lengths of stay to decline by 22.1 percent, from 3.30 to 2.57 days. In effect, part of the reduction in hospital stays was offset by the increase in severity of illness. 
Table 4. Inpatient mean lengths of stay discharges to nursing homes, Syracuse hospitals 2006-2014.

\begin{tabular}{|c|c|c|c|c|c|}
\hline & 2006 & 2008 & 2010 & 2012 & 2014 \\
\hline \multicolumn{6}{|l|}{ Adult Medicine } \\
\hline Number of Discharges & 4554 & 4940 & 5064 & 5019 & 4963 \\
\hline Mean Length of Stay & 7.56 & 7.40 & 8.20 & 8.32 & 8.91 \\
\hline Severity Adjusted National Average & 5.24 & 5.49 & 5.84 & 6.05 & 6.13 \\
\hline Length of Stay Difference & 2.32 & 1.91 & 2.36 & 2.27 & 2.78 \\
\hline Patient Days Difference & 10565.28 & 9435.40 & 11951.04 & 11393.13 & 13797.14 \\
\hline \multicolumn{6}{|l|}{ Adult Surgery } \\
\hline Number of Discharges & 3148 & 3084 & 3014 & 3127 & 3170 \\
\hline Mean Length of Stay & 10.61 & 10.50 & 10.05 & 10.28 & 10.19 \\
\hline Severity Adjusted National Average & 7.31 & 7.53 & 7.60 & 7.65 & 7.62 \\
\hline Length of Stay Difference & 3.30 & 2.97 & 2.45 & 2.63 & 2.57 \\
\hline Patient Days Difference & 10388.40 & 9159.48 & 7384.30 & 8224.01 & 8146.90 \\
\hline
\end{tabular}

Adult medicine data exclude Diagnosis Related Groups concerning surgery, obstetrics, pediatrics, psychiatry, alcohol/substance abuse treatment, rehabilitation, and all patients aged 0 - 17 years; Adult surgery data exclude Diagnosis Related Groups concerning medicine, obstetrics, pediatrics, psychiatry, alcohol/substance abuse treatment, and all patients aged 0 - 17 years; Sources: Hospital Executive Council; 3M Health Information Systems.

The combined impact of the changes in adult medicine and adult surgery lengths of stay for discharges to nursing homes, adjusted for severity of illness was identified in the patient days differences for the two services. These differences were calculated by multiplying the length of stay differences by the numbers of discharges for each service and year. They indicated the impacts of the excess patient days for discharges to nursing homes on hospital occupancy in Syracuse. Patient days differences for the combined services increased by 4.7 percent, from 20953.68 to 21944.04. The small size of this change suggested that the impact of the Difficult to Place and Subacute/Complex Care Programs effectively offset the impact of changes in severity of illness on lengths of stay for discharges to nursing homes in the two services.

\section{Discussion}

The need for increased efficiency in the delivery of health care continues to be an important concern, especially for providers. Because the delivery of care is essentially a local function, this need has a major impact on hospitals, nursing homes, and other providers at the community level.

This study described the evolution of efforts to improve the efficiency of care in the metropolitan area of Syracuse, New York. The development of these efforts proved to be especially challenging for the Syracuse hospitals because they did not have access to some of the resources that existed elsewhere. During the period of the study, the hospitals owned only 14 percent of the nursing home beds in the community a level that was reduced in 2014 with the phase out of one of the two hospital owned nursing homes. They also lacked access to a long term acute care payment mechanism, such as that which existed in some other states.

The study data described how, in these circumstances, the Syracuse hospitals worked with local nursing homes and the Hospital Executive Council to implement a number of creative mechanisms to improve the efficiency of patient movement between acute and long term care providers. These mechanisms included the exchange of data and ongoing monitoring of the movement of Difficult to Place patients, as well as financial incentives to nursing home admission of specific types of patients.

The study suggested that these mechanisms constituted "soft" approaches to improving the efficiency of patient movement. They involved voluntary participation of nursing homes and hospitals in the admission and discharge of patients with extensive care needs. Such participation was developed through ongoing coordination among the individual providers and the Hospital Executive Council. It also took advantage of competitive forces in the health care system stimulated by the need for efficiency among providers of care. 
The programs described in this study were also developed using minimal financial resources. The Difficult to Place and Subacute/Complex Care Programs were coordinated through the Hospital Executive Council, a community health planning organization and generated annual expenses of approximately $\$ 108,000$. The Subacute/ Complex Care Programs involve annual budgets of \$350,000 for hospitals with annual expenses of more than 1.5 billion dollars. The programs were also implemented through additional staff work by local hospital care management departments and nursing home admissions departments without adding positions. The programs were also implemented without the addition of another health care payor or government staff positions.

In this context, the study data suggested that the programs implemented in the health care system of Syracuse, New York appear to have been able to reduce increases in hospital stays for discharges to nursing homes and the additional inpatient days generated by these increases. For adult medicine, differences between hospital stays for discharges to nursing homes and severity adjusted national averages were consistent through the period of the study. For adult surgery, these differences declined. As a result, the excess days for adult medicine and adult surgery in the combined hospitals increased by only 4.7 percent.

It should be emphasized that these results were generated as numbers of Difficult to Place patients in the hospitals increased. More importantly, they also occurred as the numbers and severity of illness of medical-surgical patients increased, especially adult medicine patients. Both of these developments occurred as the numbers of nursing home beds and hospital owned nursing home beds in the community did not increase.

Moving forward, the Syracuse hospitals are considering revisions of the Difficult to Place and Subacute/ Complex Care Programs in order to improve their impact on lengths of stay and related health care efficiency. These include adjustments in the criteria for identifying Difficult to Place patients to focus on those with the greatest benefits to patients and impact on hospital stays. They also include refinement of types of patients supported by the Subacute and Complex Care programs in order to achieve the same objectives. Current experience suggests that these types of innovations include the greatest opportunities for improving the results of these programs within the context of available resources.

\section{References}

[1] Martin, A.B., Hartman, M., Whittle, L. and Catlin, A. (2014) National Health Care Spending in 2012: Rate of Health Spending Growth Remains Low for the Fourth Consecutive Year. Health Affairs, 33, 67-77. http://dx.doi.org/10.1377/hlthaff.2013.1254

[2] Dentzler, S. (2011) Urgent Measures for an Old Problem. Health Affairs, 30, 1626. http://dx.doi.org/10.1377/hlthaff.2011.0961

[3] Friedman, B., De La Mare, J., Andrews, R. and McKenzie, D.H. (2002) Practical Options for Estimating the Cost of Hospital Stays. Journal of Health Care Finance, 291, 1-13.

[4] Cushing, W.T. (2004) Extra Hospital Days Can Cost You Plenty. Medical Economics, 81, 83.

[5] Andersen, G. and Knickman, J.R. (2001) Changing the Chronic Care System to Meet People’s Needs. Health Affairs, 20, 146-160. http://dx.doi.org/10.1377/hlthaff.20.6.146

[6] Marek, K.D. and Rantz, M.J. (2000) Aging in Place: A New Model for Long Term Care. Nursing Administration Quarterly, 24, 1-11. http://dx.doi.org/10.1097/00006216-200004000-00003

[7] Capitman, J.A., Haskins, B. and Bernstein, J. (1986) Case Management Approaches in Community Oriented Long Term Care Demonstrations. Gerontologist, 26, 298-404. http://dx.doi.org/10.1093/geront/26.4.398

[8] Oriol, W. (1985) The Complex Cube of Long Term Care. American Health Planning Association, Washington DC.

[9] Wagner, E.H., Austin, B.T., Davis, C., Hindmarsh, M., Schaefer, J. and Bonomi, A. (2001) Improving Chronic Illness Care: Translating Evidence into Action. Health Affairs, 20, 64-78. http://dx.doi.org/10.1377/hlthaff.20.6.64

[10] Evans, M. (2012) The Early Returns on Accountable Care. Modern Healthcare, 42, S1-S5.

[11] Fisher, E.S., Shortell, S.M., Kriendler, S.A., Van Citters, A.D. and Larson, B.K. (2012) A Framework for Evaluating the Formation and Implementation of Accountable Care Organizations. Health Affairs, 31, 2368-2378. http://dx.doi.org/10.1377/hlthaff.2012.0544

[12] Lagoe, R., Pasinski, T., Kronenberg, P., Quinn, T. and Schaengold, P. (2006) Linking Health Services at the Community Level. Canada Healthcare Quarterly, 9, 60-65. http://dx.doi.org/10.12927/hcq..18229

[13] Lagoe, R.J., Westert, G.P., Kendrick, K., Morreale, G. and Mnich, S. (2005) Managing Hospital Length of Stay Reduction: A Multihospital Approach. Health Care Management Review, 30, 89-92.

http://dx.doi.org/10.1097/00004010-200504000-00002 
[14] Lagoe, R.J., Noetscher, C., Vargason, A. and Buttiglieri, M. (2008) Reducing Hospital Stays for Patients Discharged to Nursing Homes: An Evolving Program. Topics in Advanced Practice Nursing eJournal, 8.

[15] Lagoe, R., Noetscher, C., Markle, A. and Johnson, P. (2010) Community Wide Programs to Support Hospital Discharges to Nursing Homes. Topics in Advanced Practice Nursing eJournal, 10. 